\title{
Polychlorinated biphenyl contamination to the Canadian arctic from landfills and sewage treatment outlets
}

\begin{abstract}
An investigation was undertaken in soil from the Canadian polar circle [Yellowknife (YELL), Iqaluit (IQA), and Cambridge Bay (CAM)]. Twenty four soil samples (YELL = 3, $\mathrm{IQA}=15, \mathrm{CAM}=6$ ) were collected with the depths of $0 \mathrm{I} 20 \mathrm{~cm}$ below surface. Eighty major PCBs congeners were analyzed and twenty two PCBs were detected. Concentrations of PCBs in IQA were found to be the highest (0.11ї $1111 \mathrm{ng} / \mathrm{g}$ on dry weight basis), following in decreasing order: CAM (0.07ї $145 \mathrm{ng} / \mathrm{g})$ and YELL (0.4ї $7.1 \mathrm{ng} / \mathrm{g})$. Contamination profiles of PCB congeners were different between Iqaluit samples, while PCBs congener profiles were similar in Yellowknife and Cambridge Bay areas. The background sample sites were chosen to be representative of clean and undisturbed soils. The large difference in concentrations observed between dumpsites and background soil samples suggest PCB deposition into these dumpsites from materials discarded within. This is yet another evidence to show that previously pristine Polar Regions are increasingly getting contaminated through human activities. PCBs are excellent industrial markers in this forensic investigation.
\end{abstract}

Keyword: PCBs; Arctic; Forensic 